\title{
RETRIBUCIÓN COMO COACCIÓN PUNITIVA
}

\author{
Juan Pablo Mañalich R.* \\ Universidad de Chile
}

\begin{abstract}
RESUMEN: El artículo presenta una concepción de la pena jurídica como coacción retributiva, cuyas bases se encuentran en el pensamiento de Hegel y Binding. Hegel entiende la retribución como restablecimiento de la validez del derecho vía la cancelación de su propia cancelación, que es el delito. Puesto que el delito es coacción, su cancelación también ha de ser necesariamente coercitiva. El modo preciso en que la coacción retributiva se hace jurídicamente operativa puede explorarse de la mano del análisis que Binding ofrece de la posición de la pena como modalidad específica de coacción jurídica. Esta concepción de la pena como coacción retributiva hace posible examinar críticamente algunas variantes de teorías prevencionistas de la pena, así como relativizar la conexión tradicional, fundamentalmente ligada a Kant, entre retribución y deontología.
\end{abstract}

Palabras clave: Pena, Retribución, Coacción jurídica, Deontología.

ABSTRACT: The article presents an account of legal punishment as retributive coercion, which relies upon the work of Hegel and Binding. Hegel understands retribution as re-establishment of legal validity through the cancelation of law's cancelation, which is crime. Since crime is coercion, its cancelation must also be coercive. The precise way in which retributive coercion becomes legally operative can be explored by reference to Binding's analysis of the position of punishment as specific form of legal coercion. This conception of legal punishment as retributive coercion enables a critical examination of some versions of prevention-theories of punishment, as well as a relativization of the traditional link, to be traced back to Kant, between retribution and deontology.

Key words: Punishment, retribution, legal coercion, deontology.

"La coerción tiene la real representación de que ella se destruye a si misma ya en su propio concepto en que la coerción es cancelada a través de coerción; por esto, ella no solo es conforme a derecho condicionadamente, sino que es necesaria -a saber-, como segunda coerción, que es cancelación de una primera coerción". (Hegel, Grundlinien der Philosophie des Rechts, $\$ 93$. )

\section{RETRIBUCIÓN COMO REALIZACIÓN DEL DERECHO}

\section{A) LA PENA COMO RETRIBUCIÓN}

La pregunta por la superación del pasado a través del derecho encierra una trampa. La trampa consiste en que la necesidad de la superación del pasado depende de que el pasado no sea, de hecho, mero pasado, sino todavía presente. Siendo el derecho un sistema que se reproduce a través de sus propias operaciones, hay que decir que desde el punto de

\footnotetext{
* Licenciado en ciencias jurídicas y sociales, Universidad de Chile (2004); doctor en derecho, Universidad de Bonn (2008); profesor visitante de derecho penal y teoría del derecho, Universidad de Puerto Rico; dirección de correo electrónico: jpmanalic@gmail.com. Este artículo constituye un extracto de la tercera parte de una monografía inédita, titulada Terror estatal y derecho penal, de próxima publicación.
} 
vista de tales operaciones todo lo que sucede solo sucede en el presente: el pasado y el futuro solo son relevantes, simultáneamente, como horizontes temporales de operaciones necesariamente actuales ${ }^{1}$. Si el pasado fuese solo pasado, no habría necesidad de su superación, pues en ese sentido el pasado es siempre lo ya superado por definición: lo que ya pasó. En los precisos términos de Jakobs, por ende, en la superación del pasado solo puede tratarse de la superación de un presente perturbado por el pasado ${ }^{2}$.

Como el propio Jakobs observa inmediatamente, es exactamente una perturbación tal lo que explica la respuesta al delito mediante la pena. El hecho punible expresa una falta de reconocimiento de la norma quebrantada como razón eficaz para la acción, y la pena declara que esa falta de reconocimiento, que de no ser punitivamente cancelada valdría ${ }^{3}$, no cuenta como razón para una merma de la vigencia de la norma. Ciertamente, existiendo criterios institucionales para la validez de una norma, no es posible asumir que su quebrantamiento, más o menos episódico, pudiese bastar para poner en cuestión su vigencia ${ }^{4}$. Pues "del mero hecho de que se quebrante el derecho no se sigue que el derecho no sea derecho" 5 . De lo contrario, la pena no podría entenderse como consecuencia jurídica del quebrantamiento de una norma, pues entonces esta ya no existiría.

Mas el nivel de referencia de la norma de sanción jurídico-penal no es la validezcomo-pertenencia-al-sistema-jurídico de la respectiva norma de comportamiento quebrantada por el autor del delito, sino su eficacia como razón para la acción, que por definición se ve comprometida cada vez que tiene lugar un quebrantamiento imputable de esa norma ${ }^{6}$ Y más todavía: aun poniendo entre paréntesis la distinción entre validez como pertenencia a un sistema normativo y validez como vigencia fáctica de una norma, sería ingenuo asumir que los criterios institucionales que definen las condiciones de validez de normas de comportamiento como pertenecientes a un determinado sistema jurídico, fijados en lo que Hart llamaría reglas (secundarias) de reconocimiento, pudiesen ser independientes de las posibilidades de sanción coercitiva como respuesta al quebrantamiento de normas o "reglas primarias”, fijadas en lo que Hart llamaría reglas (secundarias) de adjudicación 7 . Las reglas secun-

\footnotetext{
${ }^{1}$ Luhmann, Niklas. Das Recht der Gesellschaft. -1era edición- Frankfurt del Meno, Alemania: Editorial Suhrkamp, 1993, pp. 45-46, 110 .

2 JaKOBS, Günther. Vergangenheitsbewältigung durch Strafrecht, en: IsENSEE, Josef (compilador). -1era edición- Berlín, Alemania: Editorial Duncker \& Humblot, 1992, pp. 37-38.

${ }^{3}$ Hegel, Georg Wilhelm Friedrich. Grundlinien der Philosophie des Rechts. -1era edición- Frankfurt del Meno, Alemania: Editorial Suhrkamp, 1986, $\$ 99$. Esto, porque el criterio de reconocimiento de que una pauta de conducta cuenta como norma de comportamiento vinculante para los miembros de una comunidad depende, en último término -esto es, haciendo abstracción de su correspondiente institucionalización-, del modo en que los miembros de esa comunidad reaccionan al comportamiento que se desvía de tal pauta de conducta. Ciertamente, esto no significa que la existencia de tal forma de reacción pase a ser un componente intrínseco de la norma de comportamiento en cuestión, sino que es esa forma de reacción lo que ofrece el indicio para reconocer, haciendo abstracción de los correspondientes criterios institucionales, que esa norma es una norma que impone obligaciones para los miembros de esa comunidad. Véase HART, H. L. A. El Concepto de Derecho. -1era edición- Buenos Aires, Argentina: Editorial Abeledo-Perrot, 1963, pp. 107-108.

4 Véase BASCUÑÁN, Antonio. Derechos fundamentales y derecho penal, en: SABA, Roberto (compilador). Los derechos fundamentales. SELA 2001. 1era edición, Buenos Aires, Argentina, Editores del Puerto, 2003, pp. 325 ss.

${ }^{5}$ LUHMANn, Niklas, op. cit. (n. 1), p. 86.

${ }^{6}$ KIndhäUser, Urs. Gefährdung als Straftat. -1era edición- Frankfurt del Meno, Alemania: Editorial Vittorio Klostermann, 1989, p. 134.
} 
darias de un sistema jurídico, que hacen posible la producción autorreferente de validez jurídica como prestación de ese sistema, no se dejan concebir atomistamente. La suposición de que aún sin reglas de adjudicación, incluidas normas de sanción -esto es, "reglas secundarias que especifican, o por lo menos limitan, los castigos por la transgresión" de las reglas primarias que imponen deberes de hacer o no hacer ${ }^{8}$ - todavía tendría sentido "reconocer" reglas de reconocimiento, es una suposición cuyo valor solo puede ser didáctico.

La punición es realización de validez jurídica. La posibilidad del derecho es, en términos de Hegel, la posibilidad del no-derecho, esto es, del injusto (Unrecht), que es contradicción (de una norma) del derecho. El injusto es la negación del derecho, y el injusto criminal es la negación del derecho en cuanto derecho, que se manifiesta como realización de una voluntad particular cuyo valor declarativo, desde el punto de vista del derecho, se agota en la negación del derecho 9 . El injusto criminal, como realización de una voluntad cuya pretensión es la cancelación de otra voluntad -a saber, el derecho ("abstracto")-, es siempre, por lo mismo, coercitivo ${ }^{10}$. Lo cual a su vez significa: la cancelación de esta voluntad particular contraria al derecho, por la cual el derecho se restablece a sí mismo, también ha de ser coercitiva, pues solo entonces aquella se constituye como refutación de la pretensión de validez que el hecho criminal reclama para sí. De ahí que todo orden jurídico capaz de restablecerse a sí mismo mediante la cancelación de su propia cancelación sea necesariamente coercitivo ${ }^{11}$. Esto hace posible hablar, entonces, de una concepción confrontacional de la retribución coercitiva ${ }^{12}$.

\footnotetext{
${ }^{7}$ HART, H. L. A. op. cit. (n. 3), pp. 113 y ss.

${ }^{8}$ Ibid., p. 121. Esta concepción de las normas de sanción como reglas secundarias se corresponde parcialmente con la concepción de Binding, según la cual por ley penal cabe entender "toda proposición jurídica con arreglo a la cual de un determinado delito surge o no surge [para el Estado] o bien un derecho penal subjetivo o bien un deber punitivo". BINDING, Karl. Handbuch des Strafrechts. Reimpresión, Aalen, Holanda: Editorial Scientia Verlag, 1991, pp. 175 ss., 187 ss. Por eso, según Binding, el destinatario de la norma de sanción no es el juez penal, como tampoco el órgano competente por la persecución penal, como tampoco el órgano competente por la ejecución de la pena, como tampoco el titular mismo del derecho penal subjetivo. La ley penal, esto es, la norma de sanción penal, no constituye norma imperativa alguna, sino una norma habilitante que regula la relación jurídica entre el titular del ius puniendi, que pone en vigencia la respectiva norma de comportamiento, y el autor del delito, que es el destinatario de esta norma a quien resulta imputable su quebrantamiento.

9 Hegel, Georg Wilhelm Friedrich. Grundlinien..., op. cit. (n. 3) $\$ 95$ : El delito, como expresión de una voluntad que lesiona el derecho en cuanto derecho, es un "juicio infinitamente negativo"; $₫$ 97: "Si bien la lesión del derecho en cuanto derecho tiene ya una existencia positiva, exterior, ella es en sí misma nula. La manifestación de su nulidad es la negación de aquella lesión, que de igual modo tiene existencia la realidad del derecho, como su necesidad que media consigo misma a través de la cancelación de su propia lesión”.

${ }^{10}$ Ibid., $\$ 92$.

11 Ibid., $\$$ 94: "Definir el derecho abstracto o estricto, desde el principio, como un derecho que se puede imponer coercitivamente, significa conceptualizarlo en atención a una consecuencia a la que se llega recién por el desvío del injusto”. De ahí que Mohr observe que de este modo Hegel ataca la tesis kantiana de que la autorización de la coerción se encontraría analíticamente contenida por el "concepto de derecho". MoHR, Georg. Unrecht und Strafe, en: SIEP, Ludwig (compilador). HegeL, Georg Wilhelm Friedrich. Grundlinien der Philosophie des Rechts. 1era edición, Berlín, Alemania, Editorial Akademie Verlag, 2005, pp. 102-103, con nota 2. Que el derecho abstracto resulte ser, en definitiva, necesariamente, coercitivo nada tiene que ver, en todo caso, con su descripción imperativista como un conjunto de órdenes respaldadas por amenaza. Pues como se verá más abajo, el carácter coercitivo de la pena es el de una coacción física (vis absoluta), y no el de una coacción psicológica (vis compulsiva).

12 Véase Markel, Dan. The Justice of Amnesty? Towards a Theory of Retributivism in Recovering States, en University of Toronto Law Review, No 49, 1999, pp. 421 ss.; el mismo, Are Shaming Punishments Beautifully Retributive? Retributivism and the Implications for the Alternative Sanctions Debate, en Vanderbilt Law Review $\mathrm{N}^{\circ}$ 54, 2001, pp. 2183 ss.; el mismo, Against Mercy, en Minnesota Law Review, N 88, 2004, pp. 1445 ss.
} 
Esta prestación de la pena, cuyo buen nombre es retribución, consiste en el restablecimiento de la vigencia de la norma quebrantada por el delito, mediante la cancelación coercitiva de este quebrantamiento, donde "restablecimiento" significa, dialécticamente, auténtica realización del derecho. Y esto quiere decir: sin la existencia del delito como objeto de cancelación jurídica, la validez del derecho sería precaria ${ }^{13}$. El delito, como actualización de la posibilidad del no-derecho, hace posible la autoafirmación del derecho. La necesidad del derecho encierra, por ende, la necesidad del delito ${ }^{14}$.

Hasta aquí, sin embargo, las nociones de derecho, delito y pena aparecen en el solo nivel de su determinación conceptual, esto es, como abstracciones. La consumación de la posibilidad del derecho - esto es, para decirlo con Hegel, la realización de su concepto en idea-depende de su concreción como orden efectivamente practicado, como ethos de una comunidad cuyos miembros identifican reflexivamente su voluntad particular con una voluntad que ahora se sabe general en tanto concretamente objetiva. (De ahí que la praxis de una comunidad no se pueda interpretar como derecho, más que tomando en cuenta la perspectiva de quienes se desenvuelven en esa práctica como orden vivido: "el punto de vista interno" 15 ). La realización del derecho se produce en el tránsito a una autoconciencia de la comunidad política que, reconociendo la necesidad de su propia determinación como libertad ${ }^{16}$, se vuelve eticidad, la cual, como categoría del "espíritu objetivo", se halla anticipada ya en el aparecimiento de la autoconciencia individual como categoría del "espíritu subjetivo": "el yo que es el nosotros, y el nosotros que es el yo"17.

La eticidad, que es el concepto de libertad realizado "tanto como mundo presente cuanto como naturaleza de la autoconciencia"18, encuentra su expresión definitiva en el Estado, que es así manifestación de la constitución interna de esa comunidad ${ }^{19}$. Por eso, en la arquitectura de la filosofía hegeliana el derecho es "espíritu objetivo" 20 , un espacio compartido de racionalidad práctica institucionalizada, cuya ontología, sin embargo, es irreductiblemente superviniente a la ontología del "espíritu subjetivo" 21 , lo cual quiere

\footnotetext{
${ }^{13}$ HeGEL, Georg Wilhelm Friedrich. op. cit. (n. 3), $\$ 82$.

${ }^{14}$ Véase Ibid., $\$ 81$.

${ }^{15}$ El locus clásico es HART, H. L. A. op. cit.(n. 3)., pp. 102 ss.: "el aspecto interno de las reglas".

${ }^{16}$ HEGEL, Georg Wilhelm Friedrich. op. cit. (n. 3), $\$ \$ 145,146$; el mismo, Enzyklopädie der philosophischen Wissenschaften III. - 1era edición- Frankfurt del Meno, Alemania: Editorial Suhrkamp, 1986, $\$ 484$.

17 Hegel, Georg Wilhelm Friedrich. Phänomenologie des Geistes. 1era edición, Frankfurt del Meno, Alemania, 1986, p. 145. De acuerdo con la explicación de Brandom, esto significa que solo puede haber autoconciencia allí donde emerge la reflexividad del reconocimiento de la conciencia, que es una implicación de la conjunción de la simetría y la transitividad del reconocimiento de una conciencia por parte de otra. Véase BRANDOM, Robert. Selbstbewusstsein und Selbst-Konstitution. En: Halbig, Christoph, QuANTE, Michael y SieP, Ludwig (coordinadores). Hegels Erbe. 1era edición, Frankfurt del Meno, Alemania, Editorial Suhrkamp, 2004, pp. 56 ss., 67 ss., 74 ss. Esto lleva a la conclusión de que en la autoconciencia como prestación subjetiva está implicada la existencia de una comunidad de sujetos que se reconocen recíprocamente (Ibid., p. 76).

${ }^{18}$ HeGEL, Georg Wilhelm Friedrich. Grundlinien..., op. cit. (n. 3), $\$ 142$.

${ }^{19}$ Ibid., $\$ \$ 156,257$ ss.

${ }^{20}$ Así HegEL, Georg Wilhelm Friedrich. Enzyklopädie..., op. cit. (n. 16), $\$ \$ 483$ ss.

${ }^{21}$ Hegel, Georg Wilhelm Friedrich. Grundlinien..., op. cit. (n. 3), $\$ \$ 152,258$. Véase también TaYlor, Charles. Hegel. 1era edición, Frankfurt del Meno, Alemania, Editorial Suhrkamp, 1983, pp. 495 ss. Esto sugiere, tal como lo ha mostrado Taylor, ibid., pp. 561 ss., 589 ss. , el desconocimiento que subyace a la representación vulgar de la filosofía política de Hegel como una invitación al totalitarismo.
} 
decir: el derecho se realiza a través de la agencia individual de quienes son, al mismo tiempo, destinatarios y cosostenedores de sus exigencias normativas ${ }^{22}$.

En este contexto, el derecho penal tiene por objeto el restablecimiento coercitivo de la vigencia de aquellas normas que son comunes a los miembros de la comunidad, en tanto miembros de la comunidad. Y esto significa: las normas cuyo quebrantamiento imputable es punitivamente reprochable son normas que el ciudadano llamado a responder por ese quebrantamiento ha de poder ver como suyas. En este sentido, el ordenamiento de normas de comportamiento reforzadas punitivamente, que en una democracia ha de ser derecho legislado, admite entenderse, siguiendo aquí a Duff, como derecho común ${ }^{23}$. Cuál sea la configuración específica del derecho penal de esa comunidad depende, por lo mismo, de cuál sea la configuración específica de la propia comunidad ${ }^{24}$.

Al interior del Estado, el quebrantamiento de una norma (punitivamente reforzada) deja de corresponderse meramente con el injusto imputable a una persona, titular abstracto de derechos y deberes, sino que se trata ya del injusto imputable a un ciudadano ${ }^{25}$, cuyo comportamiento frustra la expectativa de lealtad que los ciudadanos mantienen entre sí en tanto se dan normas comunes a cuyo seguimiento se comprometen recíprocamente $^{26}$. La pena expresa un reproche por la objetivación de esta falta de reciprocidad, que es el reproche de culpabilidad. El delito aquí no es solo lesión de personalidad -y esto significa: también de la personalidad del autor del delito, que al lesionar la personalidad de otro lesiona asimismo la propia- ${ }^{27}$, sino también lesión del derecho de una comunidad política, cuya cancelación, por lo mismo, se vuelve cometido de la generalidad. Este cometido es asumido institucionalmente por el juez, que aplicando la ley de la comunidad se constituye en la garantía ética de que la pena es manifestación de una voluntad que se sabe a sí misma general, ${ }^{28}$, que es lo que hace posible diferenciar la retribución de la venganza ${ }^{29}$.

\footnotetext{
22 Véase PAWLIK, Michael. Person, Subjekt, Bürger. Zur Legitimation von Strafe. -1era edición- Berlín, Alemania: Editorial Duncker \& Humblot, 2004, pp. 83 ss.

23 Duff, R.A. Punishment, Communication, and Community. - 1era edición- Nueva York, EE.UU.: Editorial Oxford University Press, 2001, pp. 59 ss. Ciertamente, la referencia a un "derecho común" resulta aquí hasta cierto punto dependiente del hecho de que Duff escriba dentro del marco de la tradición del common law. Pero esto no significa que su tematización de la noción de derecho común tenga que entenderse circunscrita a esa tradición.

${ }^{24}$ HEGEL, Georg Wilhelm Friedrich. Grundlinien..., op. cit. (n. 3), $\$ 218$.

25 Sobre esto PAWLIK, Michel. op. cit., (n. 22), pp. 76 ss. Acerca de las implicaciones de la condición de ciudadano del destinatario del reproche penal véase MaÑAlich, Juan Pablo, Pena y ciudadanía, en Estudios Públicos, Santiago, Chile, $\mathrm{N}^{\circ}$ 108, 2007, pp. 63 ss.

26 Véase MaÑalich, Juan Pablo. op. cit. pp. 142 ss., 183 ss.

${ }^{27}$ HegEL, Georg Wilhelm Friedrich. Grundlinien..., op. cit. (n. 3), $\$ 99$.

28 Ibid., $\$ 220$.

29 Ibid., $\$ 103$; el mismo, Vorlesung von $1821 / 22$, op. cit., $\$ \$ 102$ y 103 . O dicho con algo de cinismo: lo que hace posible entender la retribución judicial "como la última palabra de la venganza”. GIRARD, René. La violencia y lo sagrado. lera edición, Barcelona, España, Editorial Anagrama, 1995 p. 23. Agamben sugiere que este es el sentido en que la lex talionis se configura como forma originaria de derecho, en tanto "el ordenamiento jurídico no se levanta simplemente con la sanción de una determinada extralimitación, sino que más bien se constituye a través de la repetición de la misma acción sin que a esta siga aquella sanción, es decir, como caso excepcional”. AGAMBEN, Giorgio. Homo sacer. -1era ediciónFrankfurt del Meno, Alemania: Editorial Suhrkamp, 2002, pp. 36-37.
} 
El bosquejo precedente de la función de la pena estatal vuelve inviable su comprensión, a pesar de lo que parece sugerir el Zeitgeist, como un medio dirigido a la obtención de fines preventivos ${ }^{30}$. Una manera de dar cuenta de la inviabilidad de una concepción de la pena como medio para fines de prevención consiste en explicitar los presupuestos pragmáticos -esto es, los presupuestos de los que depende que un determinado acto estatal cuente como el hecho institucional de la imposición y ejecución de una pena- que subyacen a la idea misma de la punición retributiva como la expresión de un reproche de culpabilidad jurídica, esto es: los presupuestos que necesariamente asume quien se entiende a sí mismo -aquí: la comunidad política representada por el juez que aplica la ley penal- dirigiendo un reproche de culpabilidad a un ciudadano a través de la imposición y ejecución de la pena.

En atención al tipo de acto de habla -institucionalmente ligado- que constituye la formulación de un reproche simbolizado en la imposición y ejecución de la pena, resulta necesario asumir que el autor del reproche entiende que la razón para este se agota en el hecho de que al destinatario del reproche resulta imputable el quebrantamiento de una norma común como acción u omisión culpable, que lesiona una expectativa compartida de reciprocidad ${ }^{31}$. Del reconocimiento de este presupuesto pragmático del reproche penal, se sigue que este no puede ser utilizado instrumental o estratégicamente para la obtención de fines que trasciendan la expresión categórica de desaprobación y decepción por esa objetivación de culpabilidad como falta de reciprocidad. La imposición de la pena retributiva encierra, antes bien, una oferta incondicionada de entendimiento para con el destinatario del reproche, cuya aceptación por parte de este, sin embargo, no puede ser sino contingente ${ }^{32}$. Esto, porque la aceptación del reproche en primera persona no es algo que quepa exigir al destinatario del reproche, entendido como reproche jurídico, precisamente porque su aceptación -en primera persona- de la validez de la norma quebrantada, en el sentido de constituir un modelo de corrección para el propio comportamiento, tampoco resulta jurídicamente exigible ${ }^{33}$.

Independientemente de que el penado acepte o no esa oferta de entendimiento, la imposición de la pena, en tanto materialización de un reproche personalísimo, encierra un reconocimiento de la agencia racional del responsable como razón suficiente para la respuesta punitiva, que es la razón por la que Hegel puede llegar a decir que el autor del delito es honrado mediante la imposición de la pena: el autor del delito tiene un derecho a la pena, que se deriva, tal como mostrara Herbert Morris, de su derecho a ser reconocido

\footnotetext{
30 Véase ZACZYK, Rainer. Hat er aber gemordet, so muß er sterben. Kant und das Strafrecht, en: KUGELSTADT, Manfred (coordinador). Kant-Lektionen. Zur Philosophie Kants und zu Aspekten ihrer Wirkungsgeschichte. -1era edición- Würzburg, Alemania: Editorial Königshausen \& Neumann, 2008, pp. 247-248.

${ }^{31}$ MaÑALICH, Juan Pablo. op. cit. (n. 26), pp. 156 ss.

${ }^{32}$ Ibid., pp. 168 ss.

33 Así PAWLik, Michael. op. cit. (n. 22), p. 84. Aquí se encuentra la razón por la cual la pena retributiva no puede entenderse como penitencia secular orientada al arrepentimiento, como sin embargo ha sugerido Duff. Véase DUFF, R.A op. cit. (n. 23), pp. 106 ss.; el mismo, Penance, punishment and the limits of community, en Punishment \& Society, No 5, 2003, pp. 298 ss.
} 
como persona ${ }^{34}$. Este honor (negativo) no le es concedido, sin embargo, "si el concepto y la medida de su pena no son extraídos de su hecho mismo; como tampoco si es visto solo como un animal dañino, que ha de ser vuelto inocuo, o si es visto según los fines de la intimidación y la corrección" 35 . Y a este respecto, es irrelevante que la peligrosidad del hecho delictivo también pueda incidir como variable en la medida de la respuesta punitiva adecuada, esto es, proporcional ${ }^{36}$. Pues se trata aquí, en todo caso, de la (eventual) peligrosidad del hecho delictivo, y no de la peligrosidad del hechor.

Por eso, para Binding resultaba obvio que la necesidad de la punición jamás puede encontrarse en la personalidad del delincuente: "No es penado el ser humano, sino el criminal, no es penado el delincuente al margen de su hecho, sino como autor de su hecho" 37 . Y más todavía: Un "delincuente loco", un "delincuente nato", un "delincuente" que nunca ha cometido un delito, estos son engendros fantásticos que en ningún ordenamiento jurídico pueden encontrar un lugar ${ }^{38}$.

Que la pena pueda ser entendida como respuesta merecida al hecho punible es lo que explica que la misma, como materialización de un reproche de culpabilidad, no pueda ser entendida como la mera irrogación de un mal que compensa, en el sentido del ius talionis, el mal eventualmente producido por el hecho delictivo ${ }^{39}$. Pues la prestación retributiva, materializada en la imposición y ejecución de una pena, es ante todo un acto comunicativo que responde al delito en el único nivel de referencia en que este se deja concebir como "negación del derecho" en cuanto derecho, que es el nivel en que el delito adquiere su significado como manifestación de una falta de reconocimiento de la norma quebrantada como razón eficaz para la acción. La irrogación del mal en la que consiste fácticamente la pena solo puede ser entendida, entonces, como un dispositivo convencional que es funcional al desempeño comunicativo de la respuesta punitiva ${ }^{40}$. La pena es una respuesta institucional, simbólicamente estructurada, al delito como hecho portador de sentido, esto es, al delito entendido como hecho igualmente institucional, irreductible (pero superviniente) a un hecho puramente bruto ${ }^{41}$. Pues recién en este nivel puede

${ }^{34}$ Morris, Herbert. On Guilt and Innocence. 1era edición, Berkeley, EE.UU., University of California Press, 1976, pp. 31 ss. Véase también Duff, R.A. Trials and Punishments. 1era edición, Cambridge, Reino Unido, Cambridge University Press, 1986, pp. 262 ss.

35 HegEL, Georg Wilhelm Friedrich. Grundlinien..., op. cit. (n. 3) $\$ 100$.

36 Ibid., $\$ 218$. Así también la interpretación de KöHLER, Michael. Der Begriff der Strafe. - 1era edición- Heidelberg, Alemania: Editorial R.v. Decke \& C.F. Müller, 1986, pp. 57 ss.

37 Binding, Karl. Grundriss des Deutschen Strafrechts Allgemeiner Teil. -1era edición- Leipzig, Alemania: Editorial Felix Meiner, 1913, p. 234.

38 Ibid., pp. 229-230.

39 "Eventualmente", porque no todo hecho delictivo supone la producción de un daño, esto es, de menoscabo de un bien jurídico. ¿Tendría el verdugo que errar el blanco para así imponer la pena adecuada, de conformidad con el principio del talión, a una tentativa de asesinato?

${ }^{40}$ Mañalich, Juan Pablo. op. cit. (n. 26) pp. 136 ss., 161 ss., 174 ss. Véase también Duff, R.A Punishment..., op. cit. (n. 23)., pp. 143 ss. Esto implica, a su vez, que la determinación de las formas de irrogación de un mal punitivamente adecuadas ha de tener lugar en atención a la función expresiva de la punición, y no a la inversa, lo cual excluye la idoneidad retributiva de formas de irrogación del mal que sean inconsistentes con los presupuestos pragmáticos de la retribución, lo cual no solo afecta a la "pena" de muerte, sino también a la "pena" privativa de libertad, al menos en la medida en que su configuración institucional responda a la lógica de una medida de seguridad impuesta sobre individuos etiquetados como peligrosos.

${ }^{41}$ Mañalich, Juan Pablo. op. cit. (n. 26), pp. 164 ss. 
sostenerse que delito y pena se correspondan recíprocamente: su equivalencia se encuentra, por ende, en su respectivo valor declarativo como negación del derecho y como restablecimiento del derecho a través de la contradicción de la contradicción del derecho, respectivamente $e^{42}$.

Lo anterior no excluye, ciertamente, que la pena estatal pueda, de hecho, tener efectos preventivos. El punto crucial es que estos efectos no pueden ser conceptualizados, sin distorsionarse el sentido retributivo de la pena, como fines de su imposición y/o ejecución. Lo distintivo de toda variante de teoría prevencionista, de este modo, es su incapacidad de explicar en qué medida el delito puede constituirse en un presupuesto necesario de la imposición de la pena sin constituir, empero, su razón jurídica ${ }^{43}$. Si el delito no es sino síntoma de la necesidad de una intervención preventiva dirigida a producir seguridad prospectiva, nada permite concluir que el delito pueda ser único síntoma de esa necesidad preventiva ${ }^{44}$.

\section{C) LA ESTRUCTURA DE LA COACCIÓN PUNiTIVA}

La concepción hegeliana de la relación dialéctica entre derecho, delito y pena favorece una comprensión de esta última bajo la cual ella ha de constituir, en tanto respuesta comunicativa al quebrantamiento del derecho, una respuesta coercitiva: la pena es coacción. Es importante considerar más detenidamente la manera en que la pena se constituye, de hecho, como prestación coercitiva, lo cual resulta especialmente relevante para la crítica de la teoría de la prevención general negativa como coacción psicológica, atribuida a Feuerbach, que entiende la imposición y ejecución de la pena como el cumplimiento de una amenaza formulada en la ley penal. Una refutación concluyente de esta teoría se encuentra en la concepción retributiva de la pena ofrecida por Binding, que justamente se enmarca en su propuesta de elucidación de la modalidad de coacción jurídica que representa la pena estatal ${ }^{45}$.

El punto de partida se encuentra en la constatación de que todo ejercicio de coerción en nombre del derecho (objetivo) no puede sino constituir la realización de un derecho (subjetivo) coercitivo, cuya función es contribuir a la imposición de un determinado derecho (subjetivo) principal. Por esta razón, los derechos coercitivos pueden ser conceptualizados como derechos secundarios, esto es, derechos que hacen posible, a su vez, la imposición de determinados derechos primarios. Todo derecho coercitivo es, por lo

\footnotetext{
${ }^{42}$ Hegel, Georg Wilhelm Friedrich. Grundlinien..., op. cit. (n. 3)., $\$ 101$.

43 Para una discusión crítica de las así llamadas teorías mixtas o combinatorias de la pena, que pretenden combinar un principio de prevención como objetivo general perseguido por la punición con un principio de "retribución" -propiamente, de culpabilidad- como restricción a la punición, véase MAÑALICH, Juan Pablo. op. cit. (n. 26), pp. 128 ss., 131 ss.

44 Binding, Karl. Das Problem der Strafe in der heutigen Wissenschaft. -1 era edición- Viena, Austria: Editorial Alfred Hölder, 1877, pp. 4-5: "Una teoría del derecho penal, sin embargo, que no es capaz de decir por qué castiga, por qué solo castiga después de que se ha delinquido, por qué castiga al delincuente, a pesar de que su hecho no representa la razón jurídica de la pena, por qué en definitiva acepta que el Estado castigue al delincuente, una tal teoría no puede seguir reclamando ocupar un lugar en nuestra ciencia”.

45 Binding, Karl. Die Normen und ihre Übertretung. -3 era edición- Aalen, Holanda: Editorial Scientia Verlag, 1965, tomo I, pp. 483 ss.
} 
mismo, accesorio a un determinado derecho subjetivo principal ${ }^{46}$. Tales derechos coercitivos secundarios pueden ser o bien derechos a imponer coercitivamente el respectivo derecho principal por parte del titular de este, o bien a que otro, a saber, el Estado, ejerza coacción por cuenta de aquel -lo cual siempre es el caso una vez que se consolida el monopolio estatal sobre los medios coercitivos correspondientes ${ }^{47}$. Puesto que toda coerción es coacción sobre un ser humano a comportarse de conformidad con una voluntad ajena, toda coerción jurídica ha de ser coacción a que alguien se comporte de conformidad con un derecho subjetivo ajeno, sea en la forma de una coacción a hacer, sea en la forma de una coacción a omitir- incluida aquí la coacción a tolerar, pues tolerar (una determinada acción ajena) no es sino omitir una oposición de resistencia frente a una determinada acción ajena ${ }^{48}$.

Según cuál sea el modo de determinar el comportamiento ajeno, prosigue Binding, cabe distinguir dos formas de coacción, a saber: la física y la psíquica ${ }^{49}$. La coacción física se distingue por el hecho de que su ejercicio suprime, en el sentido de una vis absoluta, la capacidad del coaccionado de realizar una voluntad disconforme con la voluntad (del coaccionador) de cuya imposición se trata. En ella solo interviene, por ende, la voluntad del agente de la coacción, que se realiza inmediatamente a través del comportamiento que para el coaccionado resulta (físicamente) inevitable ${ }^{50}$. La coacción psíquica, por su parte, presupone exactamente lo contrario, esto es, que el coaccionador obtiene el comportamiento ajeno a través de un condicionamiento de la propia voluntad del coaccionado, que realiza la prestación impuesta bajo la motivación de evitar un mal cuya irrogación se anuncia (explícita o implícitamente) para el caso de realización del comportamiento contrario. Esto último explica la economía de la coacción psíquica, que con menos recursos es capaz de alcanzar a un círculo mucho más amplio, pero al mismo tiempo presenta su debilidad en comparación con la coacción física, cuyo éxito no está mediado por la decisión de una voluntad ajena ${ }^{51}$.

Cada una de estas dos formas de coacción se corresponde con una modalidad específica de coacción jurídica, a saber: coacción de cumplimiento y coacción de aseguramiento ${ }^{52}$. La primera es una instancia de coacción física por la cual se obtiene, inmediatamente, el comportamiento que es objeto del derecho subjetivo principal reforzado me-

\footnotetext{
46 Ibid., pp. 484-485.

47 Ibid., pp. 485-486.

48 Ibid., pp. 487-488. De aquí resulta una demarcación de los derechos principales cuya imposición puede ser idóneamente reforzada por un derecho coercitivo accesorio, entre los cuales no figura, por ejemplo, el derecho cuyo titular pasa a confundirse con el sujeto correlativamente obligado (como sería el caso, según Binding, tratándose del Estado como titular de un derecho y de una obligación de sancionar penalmente), así como tampoco figuran los derechos reales como tales, y paradigmáticamente el derecho de propiedad, a favor de cuyo titular recién puede ejercerse coerción cuando otro se entromete entre él y el objeto de su propiedad. Y por eso agrega Binding que, en rigor, no hay tal cosa como una acción puramente in rem, esto es, una acción que solo pretendiera hacer valer un derecho real como tal.

49 Ibid., pp. 489 ss.

50 Binding entendía que por esto solo podía haber coerción física a omitir o tolerar, pero no coerción física a hacer (Ibid., p. 490). Esto presupone, sin embargo, una asimetría entre la estructura del actuar y la estructura del omitir, que admite ser controvertida, lo cual, en todo caso, no necesita discutirse en este contexto.

${ }^{51}$ Ibid., p. 491.

52 Ibid., pp. 496 ss.
} 
diante el derecho coercitivo respectivo -por ejemplo-, cuando el órgano encargado de la ejecución de la resolución judicial correspondiente efectúa el embargo de la cosa debida por el deudor, recibiéndola en pago el acreedor, precisamente a modo de "cumplimiento forzado". La coacción de aseguramiento, en cambio, es una instancia de coacción jurídica que opera psíquicamente, orientándose a que el sujeto respectivamente obligado se motive a efectuar la prestación debida para así evitar la irrogación del mal amenazado para el caso contrario. La ejecución "voluntaria" de la prestación debida es asegurada, por ende, mediante la introducción del motivo de evitar ese mal -como sería el caso, por ejemplotratándose de las distintas formas de caución, en la medida en que la posibilidad cierta de la ejecución de la garantía incida motivacionalmente a favor del cumplimiento de la obligación (principal) respectiva ${ }^{53}$. (La racionalidad de la coacción de aseguramiento también admite predicarse de las sanciones típicamente administrativas, susceptibles de ser legitimadas en términos de una prestación de prevención general negativa.)

Esta contraposición entre coacción de cumplimiento y coacción de aseguramiento admite ser reformulada en términos de la distinción entre dos modalidades de acción racional con arreglo a fines, a saber: como la distinción entre una modalidad de coacción como acción instrumental y una modalidad de coacción como acción estratégica ${ }^{54}$. En ambas variantes, sin embargo, la obtención de la prestación debida mediante su realización o aseguramiento coercitivos aparece como un sustituto tosco de aquello que el titular del derecho principal correlativo puede exigir, que es, agrega Binding, el cumplimiento libremente motivado de parte del obligado. Paradójicamente, por lo mismo, la coacción (física o psíquica) se muestra como medio absolutamente inidóneo para la imposición del derecho $^{55}$, precisamente porque, en sentido estricto, el derecho solo se realiza a través de la agencia libre de los sujetos jurídicamente obligados.

Para clarificar qué forma de coacción jurídica puede representar la punición estatal, es necesario determinar primero cuál es el derecho principal a cuya imposición tendría que contribuir el ejercicio del derecho coercitivo accesorio que corresponde al Estado (en tanto titular del ius puniendi). Se trata aquí, según Binding, del derecho subjetivo del Estado que se deriva de la norma que el propio Estado dirige al ciudadano ${ }^{56}$, la cual impone a este un deber de hacer (cuando se trata de una norma de mandato) o de no hacer (cuando se trata de una norma de prohibición $)^{57}$. Mas el derecho del Estado a que el destinatario

\footnotetext{
${ }^{53}$ Lo peculiar de esta forma distintiva de coacción jurídica es que el mal amenazado, a modo de coacción de aseguramiento, consiste a su vez en un ejercicio de coacción de cumplimiento. Ibid., p. 498.

${ }^{54}$ Fundamental Habermas, Jürgen. Theorie des kommunikativen Handelns. -1era edición-, Frankfurt del Meno, Alemania: Editorial Suhrkamp, 1981, tomo I, pp. 381 ss.; el mismo, Vorstudien und Ergänzungen zur Theorie des kommunikativen Handelns. 1era edición, Frankfurt del Meno, Alemania, Editorial Suhrkamp, 1984, pp. 441, 450-51, 459 ss.

55 Binding, Karl. Die Normen..., op. cit. (n. 45), tomo I, p. 493.

56 Que no puede tratarse aquí de un derecho subjetivo de la víctima tendría que resultar suficientemente claro si se atiende a la ineficacia general del perdón del ofendido como causa de extinción de la responsabilidad penal, que bajo el Código Penal chileno solo es operativa tratándose de delitos de acción penal privada (art. $93 \mathrm{~N}^{\circ}$ 5), lo cual contrasta con la admisibilidad general de la amnistía (art. $93 \mathrm{~N}^{\circ} 3$ ) y -dejando de lado la restricción constitucional que afecta a delitos terroristas- del indulto (art. $93 \mathrm{~N}^{\circ} 4$ ).

${ }^{57}$ Binding, Karl. Das Problem, op. cit. (n. 44), pp. 12-13. Esto no supone, sin embargo, validar el modelo de oposición de las categorías "soberano" y "súbdito", que ciertamente subyace a la concepción bindingiana del Estado. Es suficiente, por el contrario, reconocer la distancia que hay entre la unificación de los roles de ciudadano de una democracia -como
} 
de la norma adecue su comportamiento a esta no es un derecho cuya satisfacción sea coercible, dado que la norma en cuestión se halla siempre dirigida a la voluntad libre de su destinatario, en el sentido de que un seguimiento de la norma solo es posible allí donde su destinatario está en posición de realizar la intención (de segundo orden) de realizar intencionalmente lo normativamente adecuado ${ }^{58}$.

De ahí que el derecho del Estado a que el destinatario de la norma adecue su comportamiento a la norma, habiéndose demostrado la imposibilidad de su satisfacción en virtud de la infracción culpable del deber correlativo, resulte sustituido por un derecho, sí susceptible de satisfacción, a que el autor del delito tolere la prestación retributiva ${ }^{59}$. Pues lo peculiar de la coacción jurídica punitiva es que ella interviene en un momento en que el cumplimiento del deber originario por parte del destinatario de la norma ya es imposible, pues la pena solo se impone, como respuesta jurídica, una vez que el delito ha sido cometido.

Dado que la ley penal -esto es, la norma de sanción penal- anuncia la irrogación de un mal para el caso de la infracción del deber impuesto por la norma de comportamiento respectiva, podría asumirse que la imposición y ejecución de la pena habrían de operar al modo de un reforzamiento de la seriedad de la conminación legal de la pena ${ }^{60}$, esto es, como medio de "coacción psicológica", precisamente en el sentido de la teoría de la prevención general negativa de Feuerbach. Pero, observa Binding, esta suposición es infundada. Pues lo que esta idea conlleva es una disociación del ejercicio del derecho coercitivo, regulado por la norma de sanción, respecto del derecho principal a cuya imposición aquel tendría que servir. El deber correlativo a este derecho principal, que es el deber que la norma de comportamiento impone a su destinatario, ya ha sido infringido, de modo que su cumplimiento ya no puede ser "asegurado" mediante la irrogación del mal anunciado en la norma de sanción, esto es, mediante la imposición y ejecución de la pena. Frente a esto todavía podría argüirse, no obstante, que lo que así se "asegura" sería el cumplimiento de un deber futuro, de parte del mismo o de otro destinatario de la norma. Pero es exactamente esta la disociación del derecho principal (correlativo a este deber originario) respecto del derecho coercitivo accesorio que Binding denuncia ${ }^{61}$, cuyo sentido entonces pasaría a ser el aseguramiento del cumplimiento de un deber que es temporal y situacionalmente distinto.

Así, la concepción de Binding redefine el sentido en que la imposición y ejecución de la pena se relaciona estrictamente con el derecho del Estado que es correlativo al deber ya infringido por el autor del delito, haciendo jurídicamente operativo el hallazgo funda-

titular de autonomía política- y de destinatario de la norma -como titular de autonomía privada- en el nivel de la justificación de la norma, de una parte, y la separación de esos mismos roles en el nivel de la aplicación de la norma, de otra. Esto hace posible entender el reproche de culpabilidad como un reproche por un déficit objetivado de fidelidad al derecho de parte de una persona no puede invocar su condición de ciudadano y, por ende, de autor de la norma, para eximirse de observar la norma en una situación en la cual ella se encuentra inmediatamente obligada por esa norma. Véase MAÑAlich, Juan Pablo. op. cit. (n. 26), pp. 183 ss., 187 ss.

58 Fundamental KindHÄUSER, Urs. op. cit. (n. 6), pp. 41 ss., 50 ss.

59 Binding, Karl. Die Normen... op. cit. (n. 45), tomo I, p. 500.

${ }^{60}$ Para lo que sigue Ibid., tomo I, pp. 498 ss.

${ }^{61}$ Ibid., p. 498: "una fatal independencia del derecho a la realización de la amenaza frente al derecho principal". 
mental de la concepción hegeliana de la pena, consistente en que a través de la punición retributiva "el derecho se reconcilia consigo mismo"62: el Estado conserva su autoridad normativa a pesar de la evidencia de la infracción (culpable) del deber del destinatario de la norma, que ya es inmodificable y por lo mismo "inexpiable", recurriendo para ello al "medio auxiliar más poderoso" que el Estado tiene a su disposición: "la conversión de derechos impracticables en derechos practicables"63. Lo que así tiene lugar es la sustitución de la prestación ya fallida por un equivalente, a saber, por la prestación consistente en tolerar la ejecución de la pena: "el padecimiento del señorío del derecho en el cuerpo del delincuente" 64 . Desde el punto de vista del derecho principal de cuya imposición se trata, la pena no es coacción de cumplimiento, pero tampoco coacción de aseguramiento, sino coacción sui generis; esto es, coacción retributiva ${ }^{65}$. La coacción retributiva, al igual que la coacción de cumplimiento, opera como coacción física ${ }^{66}$, en tanto ella realiza inmediatamente la prestación impuesta sobre el sujeto respectivamente obligado. Su peculiaridad se encuentra, sin embargo, en que la prestación así inmediatamente realizada no cuenta como cumplimiento del deber originario respectivo -ya infringido-, sino como subrogación de su incumplimiento ${ }^{67}$.

Esto no excluye, desde luego, que la imposición y ejecución actual de la pena retributiva, cuya irrogación está anunciada en la ley penal, pueda de hecho motivar al mismo o a otros destinatarios de normas de comportamiento reforzadas punitivamente a actuar, en el futuro, de modo conforme a deber en el futuro. El defecto de "la teoría del genial Anselm Feuerbach”, que entiende la ejecución de la pena como medio para el aseguramiento del efecto de la amenaza de pena, consiste en haber tomado este (potencial) "efecto reflejo" por el fin de la punición: "La realización de la acción conminada tiene, como siempre tratándose de una acción ejecutada por vía judicial, un fin racional propio: ella es o bien nueva amenaza o bien pena, y precisamente la última no es amenaza potenciada" 68 .

La racionalidad del ejercicio del derecho a la ejecución de la pena anunciada en la norma de sanción no es, de este modo, la racionalidad estratégica de una coacción de aseguramiento, sino una racionalidad distintivamente retributiva.

\footnotetext{
${ }^{62}$ HegeL, Georg Wilhelm Friedrich. Grundlinien..., op. cit. (n. 3), $\$ 220$.

63 Binding, Die Normen..., op. cit. (n.45), tomo I, p. 499.

${ }^{64}$ Ibid., p. 500.

65 Ibid.

66 Puesto que la coacción física constituye una modalidad de acción instrumental, cabría decir entonces que la coacción retributiva comparte ese carácter con la coacción de cumplimiento. Pero esto solo concierne la facticidad de la pena retributiva como irrogación de un mal coercitivamente impuesto, a modo de vis absoluta. Desde el punto de vista de su valor declarativo -esto es, atendiendo a la manera en que la privación coercitiva de un bien del hechor expresa un reproche categórico de culpabilidad- la pena retributiva constituye un caso de acción comunicativa. Al respecto MAÑALICH, Juan Pablo. op. cit. (n. 26), pp. 168 ss.

${ }^{67}$ Acerca de la sustitución de la obligación originaria del destinatario de la norma por la obligación secundaria de soportar la prestación punitiva, véase también PAWLIK, Michael. op. cit. (n. 22), pp. 90-91.

68 Binding, Karl. Die Normen..., op. cit. (n. 45), tomo I, p. 500.
} 
El debate entre teorías retribucionistas y teorías prevencionistas de la pena suele tematizarse por medio de su enfrentamiento como teorías "absolutas" y "relativas", no obstante la contraposición entre retribución y prevención no agota el catálogo respectivo ${ }^{69}$. Lo absoluto y lo relativo del fundamento de la punición se encontraría en el modo en que la pena se constituye como consecuencia jurídica del delito, esto es, como una consecuencia incondicionada que se entiende como respuesta al delito, de una parte, o como una consecuencia condicionada por la persecución de fines que trascienden la punición del culpable, de otra. Para dar cuenta del sentido preciso en que la fundamentación retributiva de la pena puede reclamar carácter absoluto, resulta imprescindible clarificar qué significa que la pena retributiva represente, en todo caso, una forma de "consecuencia jurídica".

Probablemente, la manera más obvia de aproximarse a este problema sea atendiendo a la tesis kantiana de que la ley penal constituye un imperativo categórico ${ }^{70}$. En los términos de Kant, esto significa que la norma de sanción penal constituiría un imperativo que designa la imposición de la pena, a consecuencia de la comisión de un delito, como acción "objetivamente necesaria tomada por sí misma, sin referencia a otro fin [ulterior]" 71 . De ahí que la ley penal pueda ser definida como "proposición jurídica sintética a priori del derecho público"72. Esta caracterización presupone una concepción deontológica del principio de retribución, de acuerdo con la cual la norma de sanción penal sería al mismo tiempo una norma de comportamiento dirigida a la persona competente imponiéndole un deber de sancionar al culpable.

\footnotetext{
69 Pues hay teorías absolutas de la pena que no son teorías de la retribución, a saber, todas las variantes de teorías de la expiación, conforme a las cuales el fin de la pena sería el saneamiento del delito, y no del infractor, como en las teorías de la prevención especial "positiva”. Véase Binding, Karl. Grundriss, op. cit. (n. 37), pp. 205-6, 210 ss. Análogamente JAKOBS, Günther. Strafrecht Allgemeiner Teil. -2nda edición- Berlín, Alemania: Editorial Walter de Gruyter, 1991, 1/17 ss. ${ }^{70}$ KANT, Immanuel. Die Metaphysik der Sitten. -1era edición- Frankfurt del Meno, Alemania: Editorial Suhrkamp, 1977, B 226, p. 453.

71 KANT, Immanuel. Grundlegung der Metaphysik der Sitten. -1era edición- Frankfurt del Meno, Alemania: Editorial Suhrkamp, 1977, BA 39, p. 43. Esta no es, ciertamente, la única interpretación posible. Véase por ejemplo ZACZYK, Rainer. Staat und Strafe - Bemerkungen zum sogenannten Inselbeispiel in Kants Metaphysik der Sitten, en: LANDWEHR, Götz (coordinador). Freiheit, Gleichheit, Selbstständigkeit. -1era edición- Hamburgo, Alemania: Editorial Joachim JungiusGesellschaft, 1999, pp. 82-83, donde se sostiene que lo único que Kant puede haber querido decir con ello es que la ley penal no puede ser sino una máxima de acción que se deja deducir del (único) imperativo categórico, según el cual -con arreglo a la primera de sus formulaciones- cada quien ha de actuar de modo tal que la máxima de su voluntad en todo tiempo pueda valer simultáneamente como principio de una legislación general. Esta interpretación se ve desafiada, no obstante, por el hecho de que el propio Kant, en la Crítica de la Razón Práctica, hable en plural de imperativos categóricos, que son todos aquellos imperativos no condicionados que por lo mismo valen como leyes prácticas. Véase KANT, Immanuel. Kritik der praktischen Vernunft. -1era edición- Frankfurt del Meno, Alemania: Editorial Suhrkamp, 1977, A 35-37, pp. 125-126; acerca de esto BIRnbaCHer, Dieter. Analytische Einführung in die Ethik. -2nda ediciónBerlín, Alemania, Editorial Walter de Gruyter, 2007, pp. 136 ss. Es decir, es posible asumir que la descripción de la ley penal como imperativo categórico se explica primeramente como una descripción estructural, que expresa que el imperativo de imponer la sanción penal a consecuencia de la comisión del delito no está sujeto a condición alguna que pudiera convertirlo en un imperativo hipotético. Precisamente en este sentido argumenta más recientemente ZACZYK, "Hat er aber gemordet, so muß er sterben", op. cit., p. 250. Esto no excluye, ciertamente, que con independencia de esto también pueda valer la tesis de que la ley penal habría de inferirse del imperativo categórico, esto es, del único principio del cual cabe extraer un sistema de moral "crítica".

72 ZACZYK, Rainer. Hat er aber gemordet, so muß er sterben, op. cit. (n. 30), pp. 251-252.
} 
Por más difundida que se encuentre esta concepción deontológica del principio de retribución no es la única posible. Pues el principio de retribución es neutral frente a la distinción meta-ética entre deontología y consecuencialismo ${ }^{73}$. La tesis indisponible para cualquier concepción retribucionista de la pena se halla en la idea de que la punición del culpable es buena en sí misma, y no por referencia a un fin ulterior que pudiese o tuviese que ser alcanzado mediante la imposición y ejecución de la pena; es decir, que la punición del responsable no es un bien meramente instrumental, sino un bien en sus propios términos ${ }^{74}$. Mas la verdad de esta última proposición es independiente de la verdad de la proposición (de segundo orden), según la cual la punición del responsable por un hecho delictivo constituye una acción categóricamente obligatoria para aquel a quien compete la aplicación de la ley penal ${ }^{75}$.

El análisis de este problema puede emprenderse recurriendo (una vez más) a Binding, cuyo punto de partida a este respecto consiste en la constatación de que "nada hay más humano que el derecho", para dejar así el camino libre a una concepción de la retribución jurídica irreductible tanto a representaciones de un quebrantamiento de una voluntad divina como a representaciones de un quebrantamiento de estándares de moral social. El objeto de la retribución jurídica solo puede estar constituido por el quebrantamiento de una norma jurídica ${ }^{76}$. La dificultad aparece, sin embargo, cuando se atiende a la enormidad de las instancias de injusto -esto es, de quebrantamiento del derecho- no punible. Lo cual, contra lo que parecería obvio, no admite explicarse a través de una eventual gradación de las formas de injusto, ya sea que se considere la entidad de las normas cuyo quebrantamiento puede resultar punible, o bien la magnitud de la culpabilidad de la cual puede depender la punibilidad de su quebrantamiento, ya sea que se recurra a algún criterio que incorpore ambas variables ${ }^{77}$.

\footnotetext{
${ }^{73}$ Fundamental Moore, Michael. Placing Blame. -1era edición- Nueva York, EE.UU.: Oxford University Press, 1997, pp. 155 ss. Véase también Zaibert, Leo. Zaibert, Punishment and Retribution. -1era edición- Aldershot, Reino Unido: Editorial Ashgate, 2006, pp. 175 ss. Esto ciertamente presupone una concepción del consecuencialismo que no requiere que el objetivo de cuya persecución se trata represente un bien independientemente identificable. Véase sin embargo Duff, R.A Punishment..., op. cit. (n. 23), pp. 3 ss. Situar la dicotomía deontología/consecuencialismo en el nivel de la reflexión meta-ética significa entenderla como no directamente referida a la identificación de un determinado juicio o principio moral, sino a dos formas alternativas de fundamentación de juicios o principios morales. Así BIRNBACHER, Dieter. Analytische..., op. cit. (n. 71), pp. 113 ss. Cabe observar, por lo demás, que el planteamiento tradicional del problema supone entender "deontología" en un sentido incluyente, esto es, entender como éticas deontológicas todas aquellas que fundamentan juicios y principios morales de modo no exclusivamente orientado a las consecuencias, y no, en cambio, en un sentido excluyente, esto es, de modo tal que toda ética que fundamente juicios y principios morales con orientación a las consecuencias no cuente como deontológica Ibid., pp. 116-117.

${ }^{74}$ Por esto, una fundamentación consecuencialista del principio de retribución tendría que descansar en una variante no teleológica de consecuencialismo, con arreglo a la cual la corrección moral de una acción ha de determinarse por referencia exclusiva a la cualidad moral de sus consecuencias, en circunstancias que esa cualidad moral ha de determinarse mediante la aplicación de un estándar necesariamente distinto del principio que ordena la maximización de las consecuencias favorables. Sobre esto Birnbacher, Dieter. Analytische..., op. cit. (n. 73), pp. 186 ss. Esto excluye, en todo caso, la posibilidad de una reconstrucción utilitarista del principio de retribución.

75 Véase PAWLIK, Michel. op. cit. (n. 22), pp. 96-97, para quien el sentido de una teoría retribucionista de la pena consiste en (recién) posibilitar, y no en constreñir a, la punición.

${ }^{76}$ Binding, Karl. Das Problem..., op. cit. (n. 44), pp. 6-7.

77 Ibid., pp. 9 ss.
} 
Parte de la dificultad puede encontrarse en que Binding parta de una concepción del injusto penal como quebrantamiento de una norma que no sería, propiamente, una norma jurídico-penal, sino una norma de derecho público general ${ }^{78}$. Esta tesis está íntimamente asociada a su hallazgo -que ha de ser tenido por la premisa básica de cualquier teoría mínimamente plausible del hecho punible- de que al autor del delito no puede, por definición, ser imputable un quebrantamiento de la ley penal, esto es, de la norma de sanción penal, precisamente porque a través de su comportamiento él realiza, antes bien, el presupuesto de su aplicación, o sea, el tipo delictivo correspondiente. Por ende, si ha de tener sentido la idea de que el autor del delito quebranta una norma, esta norma ha de entenderse como una norma de comportamiento -en el sentido de una regla primaria que impone deberes de omitir o de actuar- dirigida al autor, la cual representa el estándar para la ilicitud de la realización del tipo, es decir, del supuesto de hecho que figura como antecedente de la aplicación de la respectiva norma de sanción. La norma de comportamiento, por ende, no es sino la formulación contradictoria del supuesto de hecho de la norma de sanción, que se infiere pragmáticamente de esta última, pero que a la vez constituye su presupuesto lógico ${ }^{79}$.

Que la norma de comportamiento, cuyo quebrantamiento imputable constituye el injusto culpable, no se encuentre formulada explícitamente en la legislación penal, quizá alcance a explicar, en parte al menos, por qué Binding postulaba su categorización como norma de derecho público general. Pues de sostenerse, por el contrario, que estas normas -en tanto pautas de comportamiento orientadas a la evitación de determinadas formas de afectación de ciertas características o propiedades de personas, cosas e instituciones, constitutivas de "bienes jurídicos"- sí son normas genuinamente jurídico-penales, podría aparecer la tentación de atribuir al derecho penal una función (directamente) preventiva ${ }^{80}$. Pero esto sería un error. Que el criterio de legitimación de las normas de comportamiento punitivamente reforzadas consista en la evitación de determinadas formas de afectación -en términos de lesión o puesta en peligro- de bienes jurídicos, no implica que la prestación retributiva en que se concreta la aplicación de la norma de sanción en caso de quebrantamiento imputable de la norma de comportamiento respectiva haya de entenderse orientada, entonces, a fines preventivos.

La medida en que cabe entender el derecho penal como un derecho de protección de bienes jurídicos es necesariamente indirecta: la prestación retributiva, cuyas condiciones (sustantivas) se encuentran fijadas en la norma de sanción correspondiente -así como en las reglas de imputación que la complementan- asegura la vigencia de la norma de comportamiento correspondiente, que es la norma cuyo fin es la evitación de afectaciones de bienes jurídicos, como razón eficaz para la acción ${ }^{81}$. La tarea de identificar las normas cuyo quebrantamiento imputable es merecedor de respuesta punitiva admite, por lo mismo, ser entendida como una tarea de legitimación que es intrínseca al derecho

\footnotetext{
78 Binding, Karl. Die Normen..., op. cit. (n. 45), tomo I, pp. 35 ss.; el mismo, Handbuch..., op. cit. (n. 8) pp. 155 ss.

${ }^{79}$ Véase Binding, Karl. Handbuch..., op. cit. (n. 8), pp. 159, 201.

${ }^{80}$ Ibid., pp. 162-163.

${ }^{81}$ Fundamental KINDHÄUSER, Urs. op. cit. (n. 6), pp. 132 ss.
} 
penal $^{82}$. En este sentido, cabe hablar de una función auténticamente constitutiva de la legislación penal para la determinación del objeto del reproche penal, precisamente porque la legitimidad de las normas de comportamiento punitivamente reforzadas, en el marco de un Estado democrático de derecho, solo puede reconducirse al modo de su producción legal ${ }^{83}$.

Esta redefinición del estatus de las normas de comportamiento punitivamente reforzadas como normas propiamente jurídico-penales no es suficiente, empero, para neutralizar el llamado de atención de Binding. Pues en todo caso, hay que advertir que la punibilidad del quebrantamiento imputable de una norma de comportamiento -esto es, de un injusto culpable- está sujeta al filtro representado por la(s) norma(s) de sanción, que puede(n) establecer condiciones de la punibilidad extrínsecas a la constitución del injusto culpable, piénsese, por ejemplo, en las así llamadas condiciones objetivas de la punibilidad, o bien en las causas de extinción de la responsabilidad penal, tales como la prescripción y la amnistía. Y por esto, la manera en que cabe hablar de la pena como consecuencia jurídica del delito no puede conllevar la asunción mecanicista de que la pena se seguiría espontánea o inmediatamente del delito respectivo: "los seres humanos castigan a seres humanos, y no los hechos a sí mismos" 84 .

La punición es un "hecho libre" del titular del ius puniendi, esto es, del Estado, para el cual el delito solo constituye la fuente de un derecho subjetivo, correlativo al deber del penado -quien ya ha infringido, de modo reprochable, el deber impuesto por la norma de comportamiento- de tolerar la imposición y ejecución de la pena, pero no de un deber del propio Estado de castigar al responsable ${ }^{85}$. El deber punitivo estatal no surge, como sí lo hace su derecho punitivo, exclusivamente del delito, sino que está igualmente condicionado por la necesidad del Estado de reafirmar la autoridad del derecho quebrantado. Y según Binding, esto último explica que haya un espacio para el ejercicio de una prerrogativa de gracia: si el delito no solo fundamentara un derecho, sino ya un deber incondicionado para el Estado de imponer la sanción penal, entonces resultaría inconcebible que mediante una acto de gracia el Estado pudiese liberar al responsable del padecimiento de la sanción punitiva $^{86}$.

\footnotetext{
${ }^{82}$ Esto significa que la justicia retributiva constituye una categoría secundaria frente a la justicia distributiva. Véase DEL Vecchio, Giorgio. Justice. An Historical and Philosophical Essay. -1era edición- Edimburgo, Reino Unido, Edinburgh University Press, Edimburg-o, 1952, pp. 103 ss.; RAWLS, John. A Theory of Justice. -1 era edición- Oxford, Reino Unido: Oxford University Press, 1971, p. 313. Al respecto también MAÑAlich, Juan Pablo. op. cit. (n. 26), pp. 141-142.

83 Véase Mañalich, Juan Pablo. op. cit. (n. 26), pp. 180 ss.

${ }^{84}$ Binding, Karl. Problem..., op. cit. (n. 44), p. 11. Aquí se encuentra la razón por la cual Binding reprochaba a la variante hegeliana de teoría de la retribución, caracterizada como teoría de la "necesidad dialéctica", una supuesta representación mecanicista de la pena como consecuencia puramente lógica e inmediata del delito, lo cual desconocería que la imposición de la pena en todo caso presupone un doble acto del Estado en el momento de la legislación penal y en el momento de la persecución penal que culmina en el juicio. Véase el mismo Binding, Karl Grundris..., op. cit. (n. 37), pp. 205-206, 217 ss. Esta no es, sin embargo, una interpretación caritativa de la concepción de la pena de Hegel, por cuanto ella no atiende al hecho de que en los $\$ \$ 90$ y ss. de los Grundlinien la coacción punitiva se encuentra exclusivamente tematizada como momento del "derecho abstracto", sin que eso niegue que la realización del concepto del derecho en idea, como praxis ética institucionalmente mediada, encierra también una concreción de la pena como institución del Estado, en lo cual intervienen tanto la legislación (\$218) como la jurisdicción $(\$ 220)$.

85 Binding, Karl. Problem..., op. cit. (n. 44), pp. 11-13.

${ }^{86}$ Ibid., pp. 13-14.
} 
Aquí es necesario considerar la manera en que Binding entendía que podía resolverse el dilema que parece seguirse de la conjunción del carácter absoluto de la fundamentación retributiva de la pena, de una parte, con el hecho de que el Estado en principio solo esté autorizado, pero no obligado, a responder retributivamente de otra. "En principio", porque hasta aquí el énfasis ha estado puesto exclusivamente en la relación funcional entre delito y pena, en el marco de la cual el delito representa la base de una autorización para la imposición y ejecución de la pena como consecuencia jurídica. Así, puesto que, de acuerdo a Binding, el injusto culpable - esto es, el delito- solo cuenta como fuente de un derecho punitivo, y no de un deber estatal de sancionar penalmente, la fundamentación de este deber habría de encontrarse en una consideración distinta, a saber: en la necesidad de la afirmación de la autoridad del derecho ${ }^{87}$. De ahí que Binding añadiera que la legitimación de la pena siempre se presenta con la cabeza de Jano: frente al hechor ella se justifica exclusivamente como respuesta a su hecho delictivo, por la cual tiene lugar al mismo tiempo, sin embargo, el restablecimiento de la autoridad de la norma quebrantada. Y este doble condicionamiento de la imposición de la pena constituye, según Binding, el núcleo (marginal) de verdad que contienen las teorías combinatorias de la pena ${ }^{88}$, esto es, las teorías que pretenden combinar criterios de retribución y prevención como razones que legitiman la punición del culpable ${ }^{89}$.

Esta tesis resiste, sin embargo, más de una interpretación, dependiendo de cuánto se subraye la disociación o bien la identificación de ambos momentos, a saber: la retribución del hecho culpable y el restablecimiento de la vigencia de la norma quebrantada. En términos hegelianos, el restablecimiento del derecho operado mediante la punición del culpable no se deja concebir como un momento diferente de la propia prestación retributiva. En otras palabras: la retribución del hecho culpable es el restablecimiento del derecho. Y esto significa que la afirmación de la autoridad de la norma quebrantada no ha de ser entendida como un fin ulterior, para el cual la imposición y ejecución de la pena pudiese aparecer como un medio; el restablecimiento de la norma quebrantada es, antes bien, lo que la punición realiza por sí misma. Por eso Binding podía sostener, categóricamente, que el fin de la pena, entendido como restablecimiento de la autoridad del derecho mediante la retribución del hecho culpable, es necesariamente alcanzado

\footnotetext{
${ }^{87}$ Nada contradictorio hay en que el Estado pueda ser al mismo tiempo titular de un derecho y de un deber punitivo de objeto idéntico, esto es, referidos ambos al mismo hecho imputable a la misma persona, dado que en ninguna de estas posiciones su titularidad se confunde con la titularidad de la posición correlativa. Véase CAMPAGNA, Norbert. Strafrecht und unbestrafte Straftaten. -1era edición-, Stuttgart, Alemania: Editorial Franz Steiner Verlag, 2007, pp. 48 ss., quien añade, sin embargo, que entre ambas posiciones habría que reconocer una asimetría, en tanto todo deber de hacer $\mathrm{X}$ presupondría el derecho a hacer X, sin que a la inversa todo derecho a hacer X presuponga el deber de hacer X (p. 49). Campagna confunde aquí, empero, la verdad "analítica" de la proposición de que el carácter obligatorio de una acción implica su permisibilidad, sin que a la inversa permisibilidad implique obligación (véase VON WRIGHT, Georg Henrik. Norm and Action. Londres, Reino Unido: Editorial Routledge \& Kegan Paul, 1963, p. 158), con la contingencia de que una permisión pueda estar reforzada, a su vez, como derecho de alguien, Ibid., pp. 88 ss. Es decir: todo deber de hacer X implica una permisión de hacer X, pero no un derecho a hacer X.

${ }^{88}$ Binding, Karl. Problem..., op. cit. (n. 44), pp. 15-16. Este aspecto de la teoría de la pena de Binding ha sido objeto de un llamado de atención por parte de JAKOBS, Günther. Strafrecht..., op. cit. (n. 69), 1/22, nota 25.

89 Véase Supra, nota 43.
} 
con la ejecución de la pena, de modo que no puede haber fin de la pena alguno que trascienda su ejecución ${ }^{90}$.

Siendo ambos momentos idénticos, tematizar la punición como ejercicio de un derecho estatal a la retribución de culpabilidad, o bien como cumplimiento de un deber estatal de restablecimiento de la autoridad del derecho, cuyo objeto respectivo es idéntico, dependerá de cuál sea la dimensión a ser específicamente enfatizada. Pues como ya Hegel lo advertía, siendo lo distintivo de la eticidad -la consumación del derecho como orden practicado- la unificación de derechos y deberes, ${ }^{91}$, ello también ha de valer cuando se trata de derechos y deberes punitivos ${ }^{92}$.

\section{REFERENCIAS BIBLIOGRÁFICAS}

Agamben, Giorgio. Homo sacer. 1era edición, Frankfurt del Meno, Alemania, Editorial Suhrkamp, 2002.

BASCUNÁn, Antonio. Derechos fundamentales y derecho penal. En: SABA, Roberto (compilador). Los derechos fundamentales. SELA 2001. 1 era edición, Buenos Aires, Editores del Puerto, 2003.

BINDING, Karl. Das Problem der Strafe in der heutigen Wissenschaft. 1era edición, Viena, Editorial Alfred Hölder, 1877.

_- Grundriss des Deutschen Strafrechts Allgemeiner Teil. 1era edición, Leipzig, Editorial Felix Meiner, 1913.

$$
\text { - Handbuch des Strafrechts. Reimpresión, Aalen, Holanda, Editorial Scientia Verlag, } 1991 .
$$

Del Vecchio, Giorgio. Justice. An Historical and Philosophical Essay. 1era edición, Edimburgo, Edinburgh University Press, Edimburgo, 1952.

Duff, R.A. Punishment, Communication, and Community. 1era edición, Nueva York, Editorial Oxford University Press, 2001.

GIRARD, René. La violencia y lo sagrado. 1era edición, Barcelona, Editorial Anagrama, 1995.

HABERMAS, Jürgen. Theorie des kommunikativen Handelns. 1era edición, Frankfurt del Meno, Editorial Suhrkamp, 1981.

___ Vorstudien und Ergänzungen zur Theorie des kommunikativen Handelns. 1era edición, Frankfurt del Meno, Editorial Suhrkamp, 1984.

HarT, H. L. A. El Concepto de Derecho. 1era edición, Buenos Aires, Editorial Abeledo-Perrot, 1963.

Hegel, Georg Wilhelm Friedrich. Grundlinien der Philosophie des Rechts. 1era edición, Frankfurt del Meno, Editorial Suhrkamp, 1986.

Phänomenologie des Geistes. 1era edición, Frankfurt del Meno, 1986.

JAKOBS, Günther. Strafrecht Allgemeiner Teil. 2nda edición, Berlín, Editorial Walter de Gruyter, 1991.

. Vergangenheitsbewältigung durch Strafrecht. En: ISENSEE, Josef (compilador). 1era edición, Berlín, Editorial Duncker \& Humblot, 1992.

\footnotetext{
${ }^{90}$ BINDING, Karl.Grundriss..., op. cit. (n. 37), pp. 234-235.

${ }^{91}$ HeGEL, Georg Wilhelm Friedrich. Grundlinien..., op. cit. (n. 3), \$155.

${ }^{2}$ Hegel, Georg Wilhelm Friedrich. Enzyklopädie..., op. cit., $₫ 486$.
} 
KANT, Immanuel. Die Metaphysik der Sitten. 1era edición, Frankfurt del Meno, Editorial Suhrkamp, 1977.

Grundlegung der Metaphysik der Sitten. 1era edición, Frankfurt del Meno, Editorial Suhrkamp, 1977.

Kritik der praktischen Vernunft. 1era edición, Frankfurt del Meno, Editorial Suhrkamp, 1977.

KindhäUser, Urs. Gefährdung als Straftat. 1era edición, Frankfurt del Meno, Editorial Vittorio Klostermann, 1989.

KÖHLER, Michael. Der Begriff der Strafe. 1era edición, Heidelberg, Editorial R.v. Decke \& C.F. Müller, 1986.

Luhmann, Niklas. Das Recht der Gesellschaft. 1era edición, Frankfurt del Meno, Editorial Suhrkamp, 1993.

Moore, Michael. Placing Blame. 1era edición, Nueva York, Oxford University Press, 1997.

MORRIS, Herbert. On Guilt and Innocence. 1era edición, Berkeley, University of California Press, 1976.

PaWLIK, Michael. Person, Subjekt, Bürger. Zur Legitimation von Strafe. 1era edición, Berlín, Editorial Duncker \& Humblot, 2004.

RAWLS, John. A Theory of Justice. 1era edición, Oxford, Oxford University Press, 1971

CAmpagna, Norbert. Strafrecht und unbestrafte Straftaten. 1era edición, Stuttgart, Editorial Franz Steiner Verlag, 2007.

VON Wright, Georg Henrik. Norm And Action. Londres, Editorial Routledge \& Kegan Paul, 1963.

Zaibert, Leo. Zaibert, Punishment And Retribution. 1era Edición, Aldershot, Editorial Ashgate, 2006.

ZACZYK, Rainer. Hat er aber gemordet, so muß er sterben. Kant und das Strafrecht. En: KUGELSTADT, Manfred (coordinador). Kant-Lektionen. Zur Philosophie Kants und zu Aspekten ihrer Wirkungsgeschichte. 1era edición, Würzburg, Editorial Königshausen \& Neumann, 2008. 
